\section{Anita Koren}

Podiplomska študentka, Univerza na Primorskem, Fakulteta za management anita.koreno@gmail.com

\title{
Faktoring kot oblika financiranja podjetja: trg faktoringa v Sloveniji
}

Svetovno gospodarstvo, izjema ni niti slovensko, je trenutno v izredno težkem položaju, saj smo priča eni večjih gospodarskih kriz vseh časov. Začasna zaustavitev vseh poslovnih procesov med drugim vpliva tudi na zmanjšanje likvidnosti podjetij, kar ima negativne kratkoročne in tudi dolgoročne posledice na uspešnost poslovanja. Nezmožnost poravnavanja obveznosti zaradi nelikvidnosti je težava, ki lahko vodi do zmanjšanja obsega poslovanja, do prisilne poravnave ali v najslabšem primeru do prenehanja poslovanja s stečajem. Ena od oblik financiranja, ki je na voljo podjetjem za izboljšanje likvidnosti, je faktoring. V članku obravnavamo slovenski trg faktoringa.

Ključne besede: faktoring, odkup terjatev, vir financiranja, likvidnost

\section{Factoring as a Form of Company Financing: The Factoring Market in Slovenia}

The world economy, including Slovenia, is currently in an extremely difficult position, as we are witnessing one of the greatest economic crises of all time. Temporary suspension of all business processes, among other things, also reduces the liquidity of companies, which has negative shortterm and long-term consequences for business performance. The inability to settle liabilities due to illiquidity is a problem that can lead to a reduction in the volume of business, to compulsory settlement or, in the worst-case scenario, to bankruptcy. One of the forms of financing available to companies for improving liquidity is factoring, for which the Slovenian market is discussed in the article.

Keywords: factoring, purchase of receivables, source of financing, liquidity

(cc) BY-SA https://doi.org/10.26493/1854-4231.16.11-15

\section{Uvod}

Nemoteno finančno poslovanje in zagotavljanje likvidnosti sta ključnega pomena za vsako podjetje. V trenutnem obdobju gospodarskega cikla je še toliko bolj pomembno, da si podjetja pravočasno zagotovijo likvidnost in si s tem omogočijo nemoteno finančno poslovanje. Podjetja imajo pri zagotavljanju likvidnosti na izbiro več oblik financiranja in ena izmed njih je faktoring.

Zgodovina faktoringa je dolga, največji razcvet je doživel leta 2008 v času svetovne gospodarske krize. Razlogov je bilo več, eden izmed njih je bil ta, da je imelo v času gospodarske krize veliko podjetij omejen dostop do finančnih sredstev, kar jim je povzročilo težave $z$ ohranitvijo finančne stabilnosti in likvidnosti, ki so jih lahko reševali s faktoringom (Salaberrios 2016, 29).
Kot navaja Jus (2020, 13), je faktoring storitev, ki iz leta v leto raste, se razvija in nadgrajuje. Faktoring družbe pozorno spremljajo razvoj in spremembe ter jih glede na potrebe trga po novih storitvah vključujejo v svojo ponudbo. V literaturi različnih avtorjev lahko najdemo več različnih opredelitev faktoringa, saj je to specifična finančna storitev, ki združuje več storitev, ki jih za odstopnika opravlja faktor. Za opredelitev faktoringa lahko povzamemo navedbo avtorjev Makovec Brenčičeve idr. (2009, 176), ki pravi, da je faktoring sodoben finančni instrument, ki lahko zajema več storitev: financiranje, upravljanje in zavarovanje terjatev. Bistvo faktoringa je, da se s pogodbo o faktoringu opravi prenos kratkoročnih terjatev, ki nastanejo iz naslova prodaje blaga ali storitev določenemu kupcu, v upravljanje fakto- 


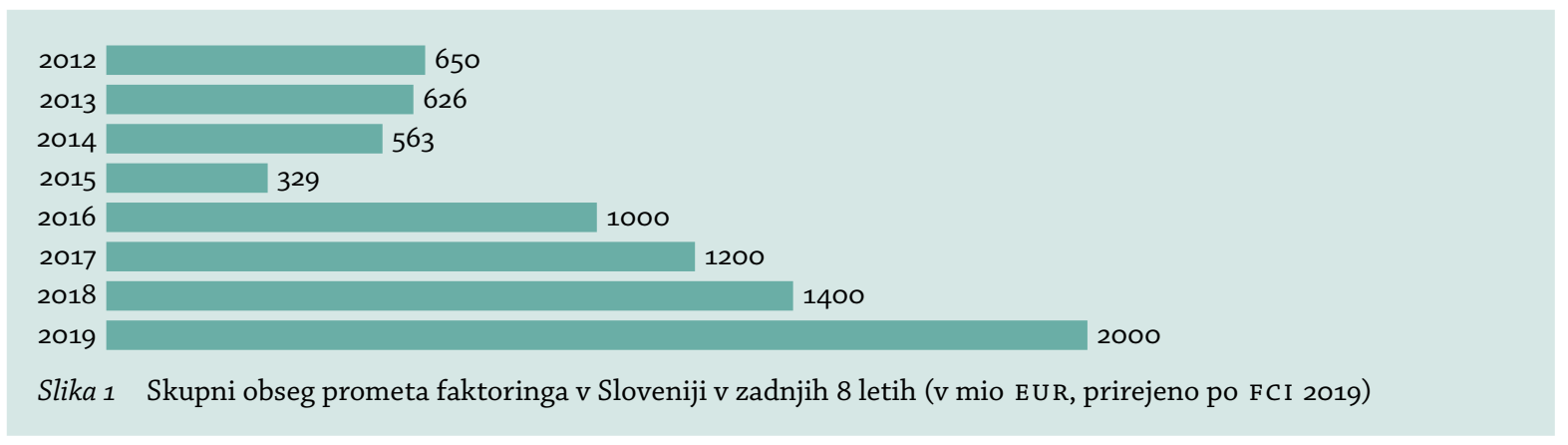

ring družbi. $\mathrm{S}$ tem podjetje terjatve $\mathrm{z}$ določenim rokom dospelosti pretvori v denarna sredstva, ki jih potrebuje za plačilo svojih obveznosti.

\section{Tržna analiza faktoringa v Sloveniji}

Nekaj podatkov o obsegu faktoringa v Sloveniji smo zasledili v domači literaturi, daleč največ pa smo jih pridobili na spletni strani združenja F CI, ki je globalno združenje za faktoring in obstaja že od leta 1968. Danes ima že blizu 400 članov v več kot 90 državah (glej https://fci.nl). Glede na raziskave domače in tuje literature zadnji trendi kažejo, da je faktoring v Sloveniji vse bolj v uporabi. Število podjetij, ki ga uporabljajo, iz leta v leto narašča. Skupni obseg prometa faktoringa v Sloveniji od leta 2012 postopoma narašča (F CI 2020). Kljub navedenemu ima Slovenija po podatkih Evropske zveze za faktoring in trgovino še vedno veliko potenciala za rast, saj še ni dosegla niti $1 \%$ tržnega deleža v Evropski uniji (v nadaljevanju EU) (EU Federation 2019, 10). Obseg faktoringa $v$ Sloveniji je majhen in predstavlja $4 \%$ bruto družbenega proizvoda (v nadaljevanju BDP). Trend je torej pozitiven, saj je obseg faktoringa leta 2014 predstavljal 1,44\% BDP (EU Federation 2016, 10), medtem ko se je v letu 2019 ta delež povečal na $4 \%$ (Ciechomska-Barczak 2020, 8).

Ocena prometa faktoringa $v$ Sloveniji za leto 2019 znaša 2,O milijarde EUR, kar predstavlja približno 43-odstotno rast v primerjavi z letom 2018. Takšno povečanje lahko pripišemo gospodarski situaciji v Sloveniji in pridružitvi Nove Ljubljanske banke, d. d. (NLB 2019), združenju F CI v letu 2019. Kljub tem trendom je slovenski obseg faktoringa s $4 \%$ BDP še precej pod evropskim povprečjem, ki je v letu 2019 ponovno presegel 11,3\% BDP EU (Ciechomska-Barczak 2020, 8). Poudariti je treba, da je informacija o prometu faktoringa $v$ Sloveniji zgolj ocena, ki je narejena na osnovi podatkov, ki jih združenju poročajo le člani združenja FCI. Trenutno so v Sloveniji pridruženi štirje člani, in sicer UniCredit Bank Slovenija, d. d., Nova Ljubljanska banka, d. d., Prva finančna agencija, d. o. o., in A.B.S. Factoring, d.o.o. (FCI 2020c). Ponudnikov faktoringa na slovenskem trgu pa je veliko več, kar pomeni, da je tudi obseg prometa faktoringa precej večji.

\section{Značilnosti faktoringa v Sloveniji}

Značilnosti faktoring trga $v$ Sloveniji je težko definirati, kajti podatkov o slovenskem trgu ne zbira nobena institucija. V opredelitvah značilnosti faktoringa $v$ Sloveniji se tako opiramo na podatke, zbrane v združenju FCI, ki jih zbirajo od članov združenja, in na članke o faktoringu, ki temeljijo zgolj na ocenah. Po javno dostopnih podatkih pa lahko ocenimo, da se tudi v Sloveniji trg faktoringa razvija in se obseg povečuje, kar potrjujemo v nadaljevanju raziskave.

Kot navaja Abdić (Banka za podjetnike 2019), se je trg faktoringa v Sloveniji v primerjavi z drugimi državami EU začel razvijati pozno. Razloga za to sta dva. Prvi razlog je visoka cena storitve $\mathrm{v}$ preteklosti, drugi razlog pa je, da smo relativno mlada država in čas inovativnih produktov v financah, predvsem $v$ manjših podjetjih, še prihaja. Abdić (Banka za podjetnike 2019) v grobem tudi ocenjuje, da faktoring občasno uporablja približno polovica slovenskih podjetij.

$\mathrm{V}$ zadnjih letih se tudi slovenski trg faktoringa informacijsko in digitalno posodablja ter razvija, kajti faktoring družbe sledijo novostim in trendom na tem področju. Na ta način si želijo pridobiti na hitrosti in s tem na konkurenčni prednosti, saj sodobna tehnologija ponuja nove rešitve in je v pomoč tako faktoring družbam kot njihovim komitentom (A.B.S. Factoring 2020).

\section{Konkurenčna analiza slovenskega nebančnega trga faktoringa}

Zgodovina faktoringa v Sloveniji sega v leto 1994, ko je bila ustanovljena prva faktoring družba LB Factors. Podjetje je delovalo kot skupno podjetje mednarodne bančne Skupine NLB in slovenske izvozno-kreditne agencije SID (NLB 2005). 
Preglednica 1 Letni prihodki faktoring družb iz nebančnega sektorja med letoma 2016 in 2019

\begin{tabular}{lrrrr}
\hline Gospodarska družba & 2016 & 2017 & 2018 & 2019 \\
\hline Prva finančna agencija, d. o. o. & 3.539 .416 & 3.433 .287 & 3.228 .917 & 3.100 .206 \\
Aleja finance, d. o. o. & 2.676 .812 & 3.041 .689 & 3.014 .630 & 3.247 .462 \\
Agencija za pospeševanje likvidnosti, d. o. o. & 1.678 .960 & 1.945 .805 & 2.493 .385 & 2.763 .819 \\
Polfin, d. o. o. & 1.838 .290 & 1.674 .454 & 1.606 .518 & 1.141 .187 \\
Borza terjatev, d. o. o. & 86.130 & 329.568 & 913.651 & 2.628 .626 \\
\hline Skupaj & 9.819 .608 & 10.424 .803 & 11.257 .101 & 12.881 .300 \\
\hline Notes Po podatkih spletnega portala Dun \& Bradstreet (https://www.dnb.com/sl-si/). & & & \\
& & & & \\
Preglednica 2 Sredstva faktoring družb iz nebančnega sektorja med letoma 2016 in 2019 & 2016 & 2017 & 2018 & 2019 \\
\hline Gospodarska družba & 33.664 .566 & 35.648 .174 & 38.913 .888 & 37.518 .073 \\
\hline Prva finančna agencija, d. o. o. & 24.725 .916 & 28.550 .181 & 31.337 .625 & 35.434 .347 \\
Aleja finance, d. o. o. & 23.944 .882 & 36.416 .461 & 30.610 .848 & 30.531 .634 \\
Agencija za pospeševanje likvidnosti, d. o. o. & 9.476 .591 & 15.844 .699 & 13.740 .787 & 14.861 .184 \\
Polfin, d. o. o. & 1.444 .648 & 4.540 .441 & 10.182 .901 & 34.151 .648 \\
\hline Borza terjatev, d. o. o. & 93.256 .603 & 120.999 .956 & 124.786 .049 & 152.496 .886 \\
\hline Skupaj & & &
\end{tabular}

Kot navaja Morozov (2014), je faktoring med slovenskimi podjetji čedalje prepoznavnejši in bolj priljubljen, kar lahko pripišemo več dejavnikom. Eden izmed teh je, da so banke po gospodarski in finančni krizi leta 2008 zaostrile pogoje financiranja in posledično bančna posojila niso bila tako enostavno dostopna kot prej. $\mathrm{Na}$ trgu se je zato pojavilo večje povpraševanje po likvidnih sredstvih, kar je prispevalo $\mathrm{k}$ temu, da se je pojavilo tudi večje število novih faktoring družb. Predvsem je na trg vstopilo večje število faktoring družb iz nebančnega sektorja pa tudi nekaj bank se je $s$ to dejavnostjo začelo intenzivneje ukvarjati. Drugi dejavnik pa je zelo koristna in prilagodljiva storitev, ki je med podjetji izredno dobro sprejeta in cenjena (N L B 2005).

V Sloveniji dejavnost faktoringa ni posebej klasificirana registrirana dejavnost, zato je težko natančno ugotoviti, koliko družb se dejansko ukvarja s to dejavnostjo in jo je zato težje natančno analizirati. Slovenski trg faktoringa lahko na grobo razdelimo na bančne faktoring družbe in faktoring družbe iz nebančnega sektorja oziroma faktoring družbe $v$ zasebni lasti. V Sloveniji deluje okoli 20 ponudnikov faktorinških storitev, več kot polovica jih je v zasebni lasti. Faktoring oziroma odkupe terjatev zagotavljajo tudi nekatere poslovne banke oziroma faktorji v lastništvu bank (»Faktoring kot instrument zagotavljanja stabilne likvidnosti« 2020).
V nadaljevanju prikazujemo analizo največjih faktoring družb iz nebančnega sektorja na podlagi javno dostopnih podatkov, pridobljenih na portalih Gvin in Ajpes:

- Prva finančna agencija, d. o. o.,

- Aleja finance, d. o. o.,

- Agencija za pospeševanje likvidnosti, d. o. o.,

- Polfin, d. o. o., in

- Borza terjatev, d. o. o.

Iz preglednice 1 je razvidno, da je bila po prihodkih v opazovanem obdobju dolga leta prva in največja med preučevanimi družbami Prva finančna agencija, d. o. o., ki pa ji prihodki v opazovanem obdobju iz leta v leto nekoliko padajo. $\mathrm{V}$ letu 2019 jo je po prihodkih prvič presegla družba Aleja finance, d.o.o., ki ji sledijo Prva finančna agencija, d.o.o., Agencija za pospeševanje likvidnosti, d. o. o., Borza terjatev, d.o.o., in kot zadnja z najmanj prihodki Polfin, d. o. o. Rast letnih prihodkov beležijo Aleja finance, d.o.o., Agencija za pospeševanje likvidnosti, d. o. o., in med vsemi družbami najhitrejšo rast letnih prihodkov v opazovanem obdobju beleži družba Borza terjatev, d. o. o., ki so se ji prihodki v letu 2019 povečali za $187,71 \%$ v primerjavi z letom 2018. Konec leta 2016 je skupna vrednost letnih prihodkov vseh opazovanih družb znašala 9,8 mio EUR in konec leta 2019 so ti znašali že 12,9 mio EUR, skupno povečanje je torej za 31,2\%. 
$\mathrm{V}$ preglednici 2 vidimo prikaz sredstev analiziranih družb, ki se iz leta $v$ leto večajo. $V$ pregledu njihovih bilanc stanja vidimo, da imajo glavnino sredstev zavedenih $\mathrm{v}$ kratkoročnih poslovnih terjatvah. Izjemi sta družbi Agencija za pospeševanje likvidnosti, d. o. o., in Borza terjatev, d. o. o., kjer je poleg sredstev treba upoštevati še zunajbilančna sredstva in jih prišteti $\mathrm{k}$ sredstvom, kar je v preglednici 2 tudi zavedeno. Vse družbe višino sredstev ohranjajo v približno enaki višini skozi celotno opazovano obdobje, izjema je Borza terjatev, d. o. o., ki beleži izredno povečanje sredstev, in sicer so se ta $v$ letu 2019 povečala za $235,4 \% \mathrm{v}$ primerjavi $\mathrm{z}$ letom 2018 . Konec leta 2016 je skupna vrednost sredstev vseh opazovanih družb znašala 93,3 mio EUR in konec leta 2019 že 152,5 mio EUR. Gre torej za skupno povečanje za $63,5 \%$.

Analizirani podatki preučevanih družb potrjujejo ugotovitve iz prvega odstavka poglavja značilnosti faktoringa $v$ Sloveniji, namreč da je dejavnost faktoringa v Sloveniji v porastu. Med opazovanimi družbami v obdobju med letoma 2016 in 2019 ugotovimo, da je največjo rast tako po prihodkih kot tudi po dobičku zabeležila družba Aleja finance, d. o. o. Iz prikazanih podatkov lahko tudi zaključimo, da so se skupni prihodki vseh družb povečali za $31,2 \%$, medtem ko se je vrednost sredstev, ki v glavnini predstavlja vrednost odkupljenih terjatev, povečala za $63,5 \%$. Podatek nam pove, da je na trgu faktoringa v Sloveniji močna konkurenca, tako $v$ primeru faktoring družb iz nebančnega kot tudi bančnega sektorja, ter posledično družbe kljub vse večjemu plasmaju sredstev iz leta $\mathrm{v}$ leto pri naložbah v povprečju dosegajo nižje prihodke, kar pomeni, da so marže vedno nižje.

\section{Sklep}

Po raziskavah UMAR (Urad Republike Slovenije za makroekonomske analize in razvoj 2020c; 2020d, 1) je epidemija novega koronavirusa v kombinaciji s strogimi zdravstvenimi in zaščitnimi ukrepi negativno vplivala na aktivnosti slovenskega gospodarstva ter mu povzročila velike težave. Povzročila je povečanje negotovosti poslovanja v vseh sektorjih.

Pozitivni sta dejstvi, da je večina podjetij krizo, povezano $\mathrm{z}$ novim koronavirusom, dočakala $\mathrm{v}$ precej boljši finančni kondiciji kot krizo leta 2008 in da so bili za ublažitev nastale gospodarske situacije hitro sprejeti številni interventni ukrepi za zajezitev nadaljnjega širjenja virusa ter ukrepi za zagotavljanje likvidnosti v gospodarstvu, med njimi (Urad Repulike Slovenije za makroekonomske analize in razvoj 2020c, 1):

- Zakon o interventnem ukrepu odloga plačil kreditojemalcev (ZIUOPOK),

- Zakon o zagotovitvi dodatne likvidnosti gospodarstvu za omilitev posledic epidemije COVID-19 (ZDLGPE) in

- različna likvidnostna posojila Slovenske izvozne in razvojne banke ter Slovenskega podjetniškega sklada (neposredno in posredno financiranje prek poslovnih bank in razmeram prilagojeni programi zavarovanj kreditov).

Kljub zgoraj navedenim ukrepom je imel izbruh krize, povezane $z$ epidemijo novega koronavirusa, negativen vpliv na poslovanje podjetij. Prizadete so bile skoraj vse dejavnosti, med njimi najbolj storitvena dejavnost, gostinstvo, promet, gradbeništvo, kultura in razvedrilo. Upad prihodkov iz poslovanja je imel negativen vpliv na plačilno sposobnost podjetij in na drugi strani na povečanje njihovih zapadlih obveznosti (Urad Republike Slovenije za makroekonomske analize in razvoj 2020c; 2020a, 3). UMAR (Urad Republike Slovenije za makroekonomske analize in razvoj 2020c; 2020b, 3) ugotavlja, da se kljub nastali krizi ni povečalo število začetih postopkov zaradi insolventnosti, število stečajnih postopkov pa se je v primerjavi $z$ enakim obdobjem lani še zmanjšalo. To pripisujejo zlasti sprejetim interventnim ukrepom, deloma pa tudi nedelovanju sodišč v času razglasitve izrednih razmer. To je lahko zaskrbljujoče, saj je lahko slika zaradi tega povsem drugačna. Zagotovo pa bodo posledice te epidemije nastopile še $\mathrm{v}$ prihodnosti, saj ni za pričakovati, da lahko ukrepi rešijo vse nastale težave podjetij, povezane $z$ epidemijo.

Faktoring družbe podjetjem pomagajo zagotavljati likvidnost s ponudbo različnih oblik faktoringa, kar je v zaostrenih gospodarskih razmerah še večjega pomena. Razvoj faktorinške dejavnosti v Sloveniji je pomemben, saj faktoring zagotovo prispeva $\mathrm{k}$ učinkovitejši alokaciji finančnih virov v gospodarstvu.

\section{Literatura}

A.B.S. Factoring. 2020. »Digitalna transformacija v finančni industriji.« https://www.abs-factoring.si/ blog/digitalna-transformacija-v-financni-industriji/.

Banka za podjetnike. 2019. "Smo vodilni ponudnik faktoringa v Sloveniji: Damir Abdić, direktor sektorja odkupa v Gorenjski banki.« https:// bankazapodjetnike.si/pogovori/smo-vodilni -ponudnik-faktoringa-v-sloveniji/. 
EU Federation. 2016. „Whitepaper: Factoring and Commercial Finance - The EU Federation for the Factoring and Commercial Finance Industry.«https://fci .nl/about-factoring/white-paper-final.pdf

- 2019. »A New Whitepaper: Factoring and Commercial Finance.« https://euf.eu.com/what -is-euf/whitepaper-factoring-and-commercial -finance.html.

Ciechomska-Barczak, M. 2020. »First Decrease in Factoring Turnover in 11 years - $2020 \mathrm{EU}$ figures. « $E U$ Federation Newsletter 19.

»Faktoring kot instrument zagotavljanja stabilne likvidnosti.« 2020. Finance, 16. april. https://pro.finance .si/8960559/Faktoring-kot-instrument -zagotavljanja-stalne-likvidnosti.

FCI. 2019. Annual Review 2019. Amsterdam: FCI. . 2020. Annual Review 2020. Amsterdam: FCI.

Jus, M. 2020. Faktoring in sorodni instrumenti financiranja trgovine. Ljubljana: samozaložba
Makovec Brenčič, M., G. Pfajfar, M. Rašković, M. Lisjak in A. Ekar. 2009. Mednarodno poslovanje. Ljubljana: Ekonomska fakulteta.

Morozov, S. 2014. »Faktoring je lahko tudi nevaren za podjetja."Dnevnik, 2. oktober.

NLB. 2005. »Deset let Prvega faktorja.« https://www .nlb.si/deset-let-prvega-faktorja.

—. 2019. "NLB postala članica združenja FCI.«https:

//www.nlb.si/ sporocilo-za-javnost-21-10-2019.

Salaberrios, I. J. 2016. »The Effects of Using Invoice Factoring to Fund a Small Business. « Doktorska disertacija, Walden University.

Urad Republike Slovenije za makroekonomske analize in razvoj. 2020a. Ekonomsko ogledalo 26 (6).

- 2020b. Ekonomsko ogledalo 26 (7).

. 2020c. Zadolženost podjetniškega sektorja. Ljubljana: UMAR.

. 2020d. Scenarij COVID-19. Ljubljana: UMAR. 